- An increasing number of patients with an implantable cardioverter-defibrillator (ICD) visit the dental practice.

- Since electrical devices potentially can interfere with the correct function of an ICD, we studied the possible interference of dental electric equipment.

- Our results suggest that normal clinical use of dental electrical equipment has no significant effects on the ICDs tested.

\title{
Interference of electrical dental equipment with implantable cardioverter-defibrillators
}

\author{
H. S. Brand, ${ }^{1}$ M. L. Entjes, ${ }^{2}$ A. V. Nieuw Amerongen, ${ }^{3}$ E. V. van der Hoeff, ${ }^{4}$ T. A. M. Schrama ${ }^{5}$
}

\begin{abstract}
Objective To determine whether electromagnetic interference with implantable cardioverter-defibrilllators (ICDs) occurs during the use of electrical dental equipment. Material and methods Ten different electrical dental devices were tested for their ability to interfere with the function of three types of ICDs at different intervals for 90 seconds, during which the ICD activity was monitored by telemetry. Results Only one ultrasonic bath cleaner interfered with two of the ICDs tested up to a distance of $12.5 \mathrm{~cm}$, both during continuous use and intermittent operation. In contrast, the dental chair, electrosurgical unit, both handpieces, ultrasonic tooth scaler, both amalgamators and two other types of ultrasonic bath cleaners failed to produce interference at the minimum distance of $2.5 \mathrm{~cm}$. Conclusion Our results suggest that normal clinical use of dental electrical equipment does not have significant effects on the ICDs tested.
\end{abstract}

\section{INTRODUCTION}

Sudden cardiac death is a major cause of mortality, often the result of heart rhythm disturbances like ventricular tachycardias (VT) or ventrical fibrillations (VF). An increasingly important treatment for patients with these lifethreatening arrhythmias is the automatic implantable cardioverter-defibrillator (ICD). This small, lithium battery-operated electronic device is surgically placed under the skin, usually near the left collar bone. One or more flexible insulated

${ }^{1}: 2$ Department of Dental-maxillofacial Surgery and ${ }^{1-3}$ Department of Dental Basic Sciences, Section of Ora Biochemistry, Academic Centre for Dentistry Amsterdam (ACTA), Amsterdam, The Netherlands; 4,5 Department of Cardiology, Academic Medical Centre (AMC), Amsterdam, The Netherlands

${ }^{*}$ Correspondence to: Dr H. S. Brand

Email:hs.brand@vumc.nl

\section{Refereed Paper}

Accepted 5 March 2007

DOI: $10.1038 /$ bdj.2007.1043

${ }^{\circ}$ British Dental Journal 2007; 203: 577-579 wires (leads) run from the ICD through the veins to the heart (Figs 1-2). The ICD monitors the heart rate continuously and when a VT or VF is detected, a precisely calibrated electrical shock is delivered to terminate the arrhythmia and restore a normal heart rate. The use of this device has cut the death rate of patients with a history of a life-threatening ventricular arrhythmia considerably. ${ }^{1}$

As ICDs are devices with elaborate electrical signals, they are potentially sensitive to electromagnetic interference (EMI) from external sources which may satisfy arrhythmia criteria. Modern life exposes us all to an increasing number of potential sources of EMI. Manufacturers try to protect the ICDs from EMI as much as possible, using features like titanium casing, signal filtering, interference rejection circuits, noise reversion function and programmable parameters. ${ }^{2}$ However, EMI may still potentially suspend detection of VT and $\mathrm{VF}$, and the undesired triggering of a shock is unpleasant or even life-threatening for the patient.

In a follow-up study of 341 patients with an ICD, EMI occurred five times in four patients ( $0.75 \%$ per patient year). ${ }^{3}$

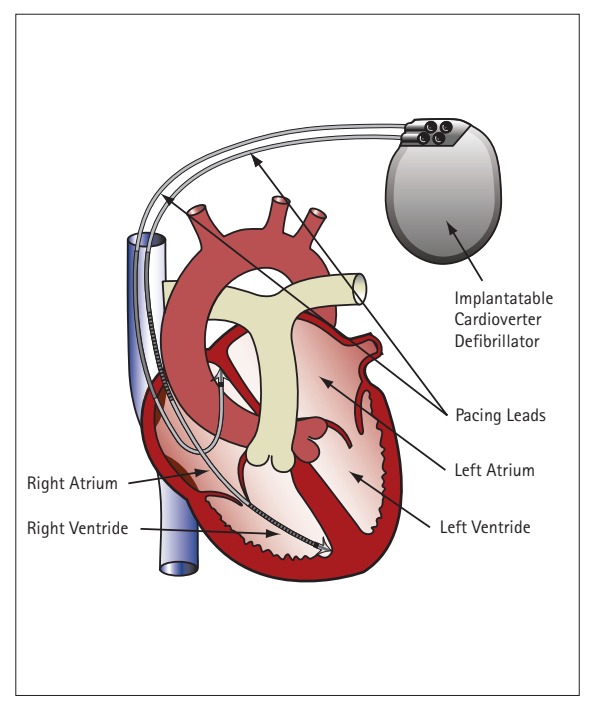

Fig. 1 An ICD is surgically placed under the skin, usually near the left collar bone (courtesy of St. Jude Medical) 
In vitro testing indicated that mobile phones could interfere with two ICDs, but during the in vivo phase of the study none of the 41 patients was affected. ${ }^{4}$ Large welding machines and electric motors did not interfere with the normal functioning of the ICDs tested, ${ }^{5}$ although one patient has been described where interference between a washing machine and an ICD resulted in inappropriate shock delivery. ${ }^{6}$

Dental equipment has been established as a source of light to moderate electromagnetic fields ${ }^{7}$ and some devices have been reported to interfere with the activity of pacemakers. ${ }^{8}$ Consequently, there is concern that EMI from dental equipment may also interfere with the correct function of ICDs. In particular, electrocautery is suspected to be a medical source of EMI. ${ }^{9-11}$ To our knowledge, no previous studies have been performed on the possible effects of dental devices on ICDs. Therefore, we investigated in vitro whether EMI with ICDs occurs during the operation of electrical dental equipment.

\section{METHODS}

During the first part of the study, several examples of commonly used dental devices were tested for their ability to interfere with the correct function of an ICD (Guidant Vitality 2 EL type VR model T177; Fig. 3). The ICD and connected leads were placed in a plastic container with 1.5 L physiological saline to simulate the electrical resistance of the human body. ${ }^{8}$ ICD output was monitored by real-time telemetry with a Guidant Zoom 2920 programmer. All dental devices were operated continuously, as well as turned on and off for 90 seconds at intervals of $2.5 \mathrm{~cm}$ both parallel to and in-line with the ICD.

Since real-time telemetry between the ICD and the programmer may be compromised by EMI, even when the device function remains normal (Pinski and Trohman, 2002), we performed an additional off-line experiment. Three ICDs (Guidant Vitality 2 EL VR T177, Medtronic Marquis DR Model 7274 and Medtronic Marquis VR Model 7230; Fig. 3) were placed in a simulator (HKP DFA2DC with HKP ARSI-2GA) to simulate the heart rate of the patient. Three different ultrasonic bath cleaners (Table 2) were operated continuously as well as on/off for 90 seconds as described above, after which the stored electrograms were reviewed off-line by telemetry with a
Guidant Zoom 2920 programmer or a Medtronic Vitratron programming head. All experiments with dental devices were performed in triplicate.

\section{RESULTS}

During the first part of the study, the dental chair and the attached electrosurgical unit, both handpieces, the ultrasonic tooth scaler and both amalgamators all failed to produce EMI at a distance of $2.5 \mathrm{~cm}$. In contrast, the Branson 200 ultrasonic bath cleaner produced EMI up to a distance of $12.5 \mathrm{~cm}$ both during continuous use and intermittent operation. During operation of the ultrasonic bath cleaner, the ICD detected several episodes of ventricular rate noise. In addition, episodes of interference with the telemetry connection between ICD and programmer were also observed ('telemetry noise').

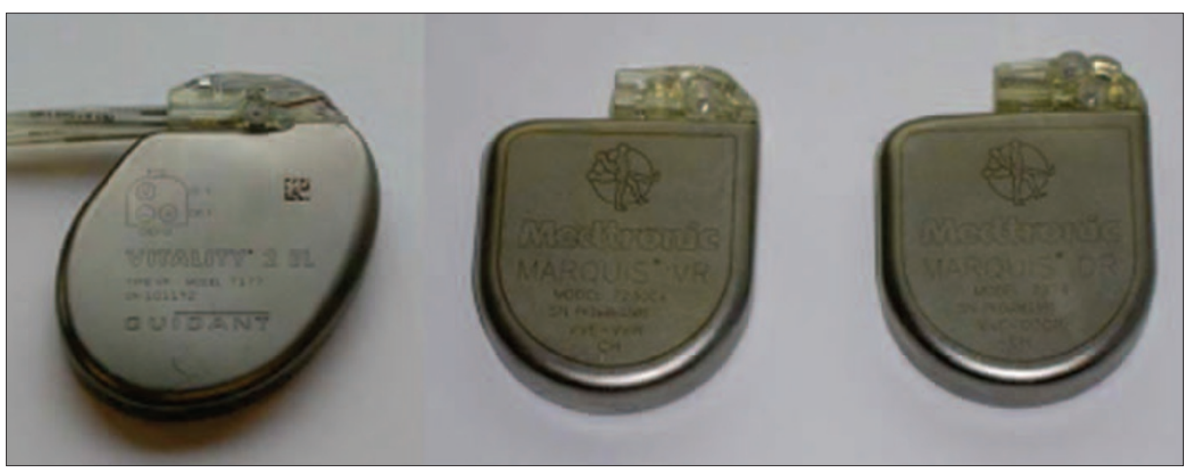

Fig. 3 The ICDs tested in this study

Table 1 Dental devices tested during the first part of the study

\begin{tabular}{l|l|l}
\hline Treatment unit & KaVo Systematica & (KaVo, Biberich, Germany) \\
\hline Electrosurgery unit & Sonosoft Lux & (KaVo, Biberich, Germany) \\
\hline Ultrasonic Scaler & Intramatic LUX 2, 24 LN, red & (KaVo, Biberich, Germany) \\
\hline Dental handpiece & Intramatic LUX 3, 7LH, green & (KaVo, Biberich, Germany) \\
\hline Dental handpiece & De Trey GB 4 & (De Trey, Konstanz, Germany) \\
\hline Amalgamator & De Trey GB 12 & (De Trey, Konstanz, Germany) \\
\hline Amalgamator & Branson 200 & (Branson, Danbury CT, USA) \\
\hline Ultrasonic bath &
\end{tabular}

Table 2 Ultrasonic bath cleaners tested during the second part of the study

\begin{tabular}{l|l}
\hline Ultrasonic bath cleaner Branson 200 & (Branson, Danbury CT, USA) \\
\hline Ultrasonic bath cleaner Bransonic 221 & (Branson, Danbury CT, USA) \\
\hline Ultrasonic bath cleaner Sonorex RK 100 & (Bandelin, Berlin, Germany)
\end{tabular}


ICDs tested (Guidant Vitality 2 EL VR T177, Medtronic Marquis DR Model 7274, Medtronic Marquis VR Model 7230).

\section{DISCUSSION}

To our knowledge, this in vitro study is the first to investigate EMI with ICD during operation of dental equipment. The findings in this study indicate that EMI generated by most dental equipment does not interfere with normal functioning of the ICDs. The single exception was a Branson 200 ultrasonic bath cleaner, which induced EMI at a short distance in both the Guidant Vitality 2 EL VR T177 and the Medtronic Marquis DR Model 7274. The EMI resulted in several episodes of ventricular noise in the ICD. Although the observed ventricular signal did not satisfy VT of VF criteria of the ICD, it may temporarily suspend the correct ventricular arrhythmia detection. Since this effect was also observed in stored electrograms, it is not an effect on the telemetry between the ICD and the programmer.

The suggestion that some ultrasonic bath cleaners are a potential source of EMI is supported by the observation that two other types of ultrasonic bath cleaners inhibited the correct function of pacemakers up to a distance of $30 \mathrm{~cm}^{8}$ Precaution in using ultrasonic bath cleaners around ICD patients seems advisable. However, this may be more of concern to dental healthcare workers with an implanted ICD, since ultrasonic bath cleaners are usually located more than $1 \mathrm{~m}$ from patient-care areas.

\section{CONCLUSION}

The findings of this study suggest that dental equipment, commonly used in the dental office, does not have significant effects on the ICDs tested. This is certainly the case when the general precaution is followed to keep electrical appliances at least $10-15 \mathrm{~cm}$ away from an ICD and its leads. ${ }^{10,12,13}$

1. Kumar P, Clark M. Clinical medicine, $5^{\text {th }}$ ed. Edinburgh: WB Saunders, 2002.

2. Sweesy M W, Holland J L, Smith K W. Electromagnetic interference in cardiac rhythm management devices. AACN Clin Issues 2004; 15: 391-403.

3. Pinski S L, Trohman R G. Interference in implanted cardiac devices. Part I. Pacing Clin Electrophysiol
2002; 25: 1367-1381.

4. Fetter J G, Ivans V, Benditt D G, Collins J. Digital cellular telephone interaction with implantable cardioverter-defibrillators. J Am Coll Cardiol 1998 31: 623-628.

5. Fetter J G, Benditt D G, Stanton M S. Electromagnetic interference from welding and motors on implantable cardioverter-defibrillators as tested in the electrically hostile work site. J Am Coll Cardiol 1996; 28: 423-427.

6. Kolb C, Schmieder S, Schmitt C. Inappropriate shock delivery due to interference between a washing machine and an implantable cardioverterdefibrillator. J Interv Card Electrophysio/ 2002; 7: 255-256.

7. Brown D M, Bennet R R. Effect of dental ultrasonic electromagnetic interference on the cardiac pacemaker. J Dent Res 1997; 76: 2197.

8. Miller C S, Leonelli F M, Latham E. Selective interference with pacemaker activity by electrical devices. Oral Surg Oral Med Oral Pathol Oral Radiol Endod 1998; 85: 33-36.

9. Dawes J C, Mahabir R C, Hillier K et al. Electrosurgery in patients with pacemakers/implanted cardioverter defibrillators. Ann Plast Surg 2006; 57: 33-36.

10. Niehaus, M, Tebbenjohanns J. Electromagnetic interference in patients with implantable pacemaker or cardioverter-defibrillators. Heart 2001; 86: 246-248.

11. Pinski S L, Trohman R G. Interference in implanted cardiac devices. Part II. Pacing Clin Electrophysiol 2002; 25: 1496-1509.

12. Corbucci C, Marton F, Riva U, Sciotto F, Venturini D. Interference and implantable cardiac stimulators. Phys Med 2004; 20: 3-12.

13. Kobe J, Gradaus R, Zumhagen S, Bocker D. Restrictions for ICD patients in daily life. Herz 2005; 30: 625-629. 